\title{
PPAR $\gamma$ is functionally expressed in clear cell renal cell carcinoma
}

\author{
NICOLAS COLLET, SANDRINE THÉOLEYRE, JULIE RAGEUL, STÉPHANIE MOTTIER, \\ FLORENCE JOUAN, NATHALIE RIOUX-LECLERCQ, PATRICIA FERGELOT, \\ JEAN-JACQUES PATARD, DAMIEN MASSON and MARC G. DENIS
}

CNRS UMR 6061, Institut de Génétique et Développement, Université Rennes 1, 35043 Rennes, France

Received September 8, 2010; Accepted November 5, 2010

DOI: $10.3892 /$ ijo. 2010.891

\begin{abstract}
Peroxisome proliferator-activated receptor gamma (PPAR $\gamma)$ agonists have been demonstrated to exert an inhibitory effect on cell growth in several tumor models, including clear cell renal cell carcinoma (CCRCC). PPAR $\gamma$ has therefore been proposed to be a potential therapeutic target. Thus, the PPAR gene must be expressed and not altered in cancer cells. We have therefore analyzed tumor specimens collected from 63 patients with CCRCC who underwent partial or total nephrectomy. The multiplex ligation-dependent probe amplification (MLPA) assay was used to detect deletions in the PPAR $\gamma$ gene. The majority of the tumors $(48 / 63 ; 76.2 \%)$ did not present alterations. Two samples (3.2\%) presented a deletion of the non-coding exon A1. Nine samples (14.3\%) showed large heterozygous deletions in chromosome $3 \mathrm{p}$ including PPAR $\gamma$. Potential mutations were analyzed by DNA sequencing of the 6 coding exons of the PPAR $\gamma$ gene. No mutation was found in exons 1-5. In exon 6, a silent polymorphism was detected in 14 samples $(22.2 \%)$. CCRCC were found to express the PPAR $\gamma 1$ isoform. The expression level of PPAR $\gamma$ was measured by real-time quantitative PCR. A significantly reduced transcript level was associated with an elevated Fuhrman grade. Finally, we analyzed the expression of angiopoietin-like 4, a known PPAR $\gamma$ target gene, in CCRCC cell lines cultured in the presence of rosiglitazone, a PPAR $\gamma$ agonist. A strong induction was found in the 3 cell lines tested, indicating that $\operatorname{PPAR} \gamma$ is functional in all these cell lines. In conclusion, we show here that PPAR $\gamma$ is expressed and functional in CCRCC, prerequisites for being a potential target for CCRCC treatment.
\end{abstract}

Correspondence to: Professor Marc Denis, INSERM U913, Faculté de Médecine, 1 rue Gaston Veil, 44035 Nantes, France

E-mail:marc.denis@univ-nantes.fr

Abbreviations: PPAR $\gamma$, peroxisome proliferator-activated receptor gamma; RCC, renal cell carcinoma; CCRCC, clear cell RCC; MLPA, multiplex ligation-dependent probe amplification

Key words: peroxisome proliferator-activated receptor $\gamma$, clear cell renal cell carcinoma, multiplex ligation-dependent probe amplification

\section{Introduction}

Renal cell carcinoma (RCC) accounts for 3\% of all solid tumors. It is the sixth leading cause of cancer related deaths due to the lack of effective therapy for locally advanced or metastatic disease (1). Seventy-five percent of RCC are clear cell carcinomas (CCRCC). Important progress in the biology of these tumors has been made. In particular, the loss of function of the von Hippel-Lindau $(V H L)$ tumor suppressor gene is involved in $\sim 70 \%$ of sporadic CCRCCs. The biallelic disruption of the $V H L$ gene leads to dysregulation of target genes, such as the vascular endothelial growth factor (VEGF), a central mediator of tumor angiogenesis. Consequently, significant progresses have been made in the medical treatment of metastatic RCC by targeting a number of growth factors, including VEGF, platelet-derived growth factor (PDGF) and their receptors $(2,3)$. Indeed, median progression-free survival time has been doubled either in first line or in second line therapy by targeting tumor angiogenesis (4).

Peroxisome proliferator-activated receptor gamma (PPAR $\gamma)$ is a member of the nuclear receptor superfamily of ligandactivated transcriptional factors (5). PPAR $\gamma$ is expressed in a variety of normal tissues where it plays an important role in metabolic diseases, and cancer (6-8). PPAR $\gamma$ is also highly expressed in many tumors and cancer cell lines derived, for instance, from colon (9), breast (10), lung (11), thyroid (12) and gastric (13) tumors. PPAR $\gamma$ agonists have been extensively investigated as potential anti-tumor drugs, and they have been shown to inhibit growth of malignant human cells, and cause cell cycle arrest and apoptosis in a broad spectrum of epithelial derived tumor cell lines in vitro $(14,15)$. In vivo, synthetic PPAR $\gamma$ agonists, such as the thiazolidinediones decrease the development of tumors in xenograft models $(9,16,17)$. PPAR $\gamma$ ligands also induce cell cycle arrest and apoptosis in human CCRCC cell lines (18-20), and reduce the production of potent angiogenic factors such as VEGF and FGF (18). These observations demonstrate that PPAR $\gamma$ agonists are inhibitors of angiogenesis and altogether, these data suggest that PPAR $\gamma$ ligands agonists may have promise in CCRCC treatment.

The PPAR $\gamma$ gene is located on chromosome 3 (3p25) (21), close to the VHL (von Hippel-Lindau) tumor suppressor gene located in band 3p25-26 (22). The VHL gene is frequently deleted in CCRCC (23-25), and therefore we performed allelic 
quantification using MLPA to determine whether the PPAR gene was also deleted. We also sequenced all the common coding exons of PPAR , and then tested PPAR $\gamma$ expression in CCRCC by RT-PCR and immunoblotting. Finally, we treated CCRCC cell-lines with a PPAR $\gamma$ agonist to induce the expression of target genes. We show here that PPAR $\gamma$ is expressed and functional in $\mathrm{CCRCC}$, prerequisites for being a potential target for CCRCC treatment.

\section{Materials and methods}

Tumor specimens. A total of 63 patients operated for a sporadic CCRCC in the Department of Urology at the Rennes University Hospital between 2003 and 2005 were analyzed. The study protocol was approved by the institutional ethics committee and informed consent for participating in this study was obtained in each case. The following variables were prospectively noted: age, gender, TNM stage, ECOG performance status.

Macroscopic and histologic parameters analyzed included tumor size, tumor necrosis and nuclear Fuhrman grade $(26,27)$. Tumor stage was defined according to the pTNM classification $(28,29)$.

Tumors from untreated patients undergoing partial or total nephrectomy were analyzed. Immediately after macroscopic examination, small tumor non-necrotic sample were collected from surgical specimens, frozen in liquid nitrogen and stored at $-80^{\circ} \mathrm{C}$.

Multiplex ligation-dependent probe amplification (MLPA). DNA was extracted from snap-frozen tumors using the iPrep gDNA Tissue kit (Invitrogen, Carlsbad, CA, USA), after histological control. The multiplex ligation-dependent probe amplification (MLPA) method was used to establish the copy number of several nucleic acid sequences in a semi-quantitative manner (30).

MLPA was performed using the SALSA MLPA P224 kit (MRC-Holland, Amsterdam, The Netherlands). Details on probe sequences, gene loci and chromosome locations can be found at www.mlpa.com. This assay allows to detect deletions or duplications in the PPAR gene. The probes of the kit target each of the nine PPAR $\gamma$ exons (31). Control probes targeted genes located in band 3p25: GHRL (GHrelin) and XPC (Xeroderma Pigmentosum Group $C$ ). Genomic DNA (50-200 ng) was denatured and the probes were allowed to hybridize $\left(16 \mathrm{~h}\right.$ at $\left.60^{\circ} \mathrm{C}\right)$. After ligation, PCR was performed on the samples in a volume of $50 \mu \mathrm{l}$ containing $10 \mu \mathrm{l}$ of the ligation reaction mixture using the PTC 200 thermal cycler (MJ Research, Waltham, MA, USA). Aliquots of $1.5 \mu \mathrm{l}$ of the PCR reaction were combined with $0.3 \mu$ l ROX-labeled internal size standard (Applied Biosystems, Foster City, CA) and $9 \mu \mathrm{l}$ deionized formamide. Fragments were separated by electrophoresis on an Applied 3130XL capillary sequencer and quantified using the GeneMarker version 1.6 software (SoftGenetics, State College, PA). For copy number detection, normal control DNA samples were included in each set of MLPA experiments. Interpretation was based on the comparison of peak heights between the tumor sample and the control DNA (r, ratio). The cut-off level for relative loss of copy number was set at $\mathrm{r}=0.8$.
DNA sequencing. The six common PPAR $\gamma$ (NM_138711) coding exons have been analyzed. The primers used will be given on demand. PCR clean-up was performed using ExoSAP $^{\circledR}$ (USB Corp., Cleveland, OH). Sequencing was performed using standard procedures with the BigDye ${ }^{\circledR}$ Terminator v3.1 kit (Applied Biosystems). The CodonCode Aligner software (CodonCode Corp., Dedham, MA) was used for sequencing analysis.

RNA extraction, cDNA synthesis and qualitative RT-PCR. Total RNA was extracted from snap-frozen tumors using the QIAamp total RNA kit (Qiagen, Hilden, Germany) after histological control. Integrity of RNA samples was controlled by analysis on Agilent 2100 Bioanalyzer (Agilent Technologies, Santa Clara, CA). Following analysis, an RNA integrity number (RIN) was calculated. Only RNA with a RIN $>8$ were further processed and used for cDNA synthesis as previously described (32).

The relative expression of human $\operatorname{PPAR} \gamma$ variants was studied by RT-PCR, using oligonuleotides which allowed us to distinguish between PPAR $\gamma 1$ and $\gamma 2$ mRNA (Fig. 2A). The sequence of these primers are available upon request. PCR amplifications were performed using the LC480 SYBR Green I Master mix (Roche Diagnostics, Meylan, France) in a Rotorgene 3000 instrument (Corbett Research, BioLabo, Archamps, France). The reaction mixture contained $10 \mu 1$ of the supplied $2 \mathrm{x}$ mix, $0.5 \mu 1$ of each primer (final concentration $0.25 \mu \mathrm{M}$ each), $9 \mu \mathrm{l}$ of the template (cDNA diluted 1/40). The cycling conditions were as follows: denaturation for $5 \mathrm{~min}$ at $95^{\circ} \mathrm{C}$; amplification for 35 cycles, with denaturation for $5 \mathrm{sec}$ at $95^{\circ} \mathrm{C}$, annealing for $5 \mathrm{sec}$ at $63^{\circ} \mathrm{C}$ and extension for $5 \mathrm{sec}$ at $72^{\circ} \mathrm{C}$. Amplicons were then analyzed by gel electrophoresis on $10 \%$ polyacrylamide gels (Invitrogen).

Quantitative RT-PCR. Real-time PCR was performed according to previous reports (33). Primers were designed from the sequence of the human cDNAs using the Universal ProbeLibrary Assay Design Center (https://www.rocheapplied-science.com/sis/rtpcr/upl). They were selected for binding to separate exons to avoid false-positive results arising from amplification of contaminating genomic DNA. We verified that all amplifications did not yield any product when reverse transcriptase was omitted in the cDNA synthesis reaction. The sequences of these primers are available upon request. PCR amplifications were performed as described above. The cycling conditions were as follows: denaturation for 5 min at $95^{\circ} \mathrm{C}$; amplification for 35 cycles, with denaturation for $5 \mathrm{sec}$ at $95^{\circ} \mathrm{C}$, annealing for $5 \mathrm{sec}$ and extension for $5 \mathrm{sec}$ at $72^{\circ} \mathrm{C}$. To exclude primer-dimer artifacts, fluorescence was not measured at the end of the extension step, but a separate detection step was added $(10 \mathrm{sec})$ at a temperature above the melting point of primer-dimers and below the melting point of the specific PCR product. A standard curve was generated with serial dilutions of pooled cDNAs samples. The amount of transcripts was calculated from these standard curves using the RotorGene software. For each sample, the ratio between the relative amount of each specific transcript and $\beta$-actin was then calculated to compensate for variations in quantity or quality of starting mRNA as well as for differences in reverse transcriptase efficiency. 
Table I. Clinicopathologic characteristics of the 63 CCRCC patients.

\begin{tabular}{lc}
\hline Age (years) & $63.8(21-83)$ \\
Gender & \\
Male & $36(57.1 \%)$ \\
Female & $27(42.9 \%)$ \\
Fuhrman grade & \\
1 & $1(1.6 \%)$ \\
2 & $21(33.3 \%)$ \\
3 & $24(38.1 \%)$ \\
4 & $17(27.0 \%)$
\end{tabular}

Tumor stage

1

2

3

4

$20(31.7 \%)$

$11(17.5 \%)$

$29(46.0 \%)$

$3(4.8 \%)$

Lymph node status
0
$50(79.3 \%)$
1 or $2(+)$

Metastasis status

0

$+$

Values are presented as median (minimum-maximum) for continuous variables and number of patients (percent) for categorical variables.

Western blot analysis. Total protein $(12 \mu \mathrm{g})$ extracted from 24 samples (786-O cell-line and 23 CCRCC) was separated by polyacrylamide gel electrophoresis and transferred onto a nitrocellulose membranes. The membranes were then probed overnight with a rabbit anti-mouse $\operatorname{PPAR} \gamma$ monoclonal antibody (Calbiochem, Darmstadt, Germany) diluted 1:2,000. The membrane was then incubated for an hour with the secondary 1:5000 goat anti-rabbit IRDye ${ }^{\circledR}$-linked antibody then analyzed with the Odyssey infrared imaging system (LI-COR, Lincoln, NE). Normalization was performed using an anti-ß-actin antibody.

Cell culture and rosiglitazone treatment. Three CCRCC cell lines (786-O, Caki-2 and RCC4) were used. RCC4 and 786-O are VHL-defective CCRCC cell lines, whereas Caki-2 express functional VHL. The cell lines were cultured in DMEM (Invitrogen) supplemented with $10 \%$ fetal bovine serum. Rosiglitazone was dissolved in DMSO and used at a final concentration of $10 \mu \mathrm{M}$. The final DMSO concentration in culture medium of all experiments was kept constant at $0.05 \%$. Cells were exposed to this ligand for $24 \mathrm{~h}$. Total RNA was then extracted and cDNA synthesized. Induction of ANGPTL4 was evaluated by quantitative RT-PCR using GAPDH as normalization control. Statistical analysis was performed with the Mann-Whitney U test.

\section{Results}

We analyzed tumors obtained from 63 patients with CCRCC who underwent partial or total nephrectomy between 2003 and 2005. The main clinical features are presented on Table I.

$M L P A$. CCRCC frequently present deletion of the $V H L$ gene $(23,25)$. In our cohort, $70 \%$ of the patient samples were previously shown to present deletions of the $V H L$ gene as determined by MLPA (24). As PPAR $\gamma$ is located in closed proximity to $V H L$, on band 3p25 (21), we first performed PPAR $\gamma$ MLPA analysis using a specifically designed assay to assess a potential allelic loss. Fig. 1A presents the results obtained with DNA extracted from normal kidney as a control. The 63 tumor samples were analyzed. Forty-eight samples (76.2\%) presented a normal pattern without any deletion (Fig. 1B). Nine samples (14.3\%) showed large heterozygous deletions in chromosome $3 p$ (Fig. 1C). Two samples (3.2\%) presented a deletion of the non-coding exon A1: one was homozygous $(r=0.22)$ and the other one was heterozygous $(\mathrm{r}=0.6)$. Finally, 4 tumors $(6.3 \%)$ presented deletions of $X P C$ : one was homozygous $(\mathrm{r}=0.24)$ and the other 3 were heterozygous (mean $\mathrm{r}=0.57$ ). In conclusion, a limited number of tumors $(14.3 \%)$ presented a deletion of the PPAR $\gamma$ gene, and this was always heterozygous.

$D N A$ sequencing. Point mutations of the PPAR gene have been described in solid tumors $(34,35)$, but RCC have not yet been tested. In order to determine whether the PPAR gene was mutated in these tumors, we sequenced the six $P P A R \gamma$ coding exons in our series of tumors. No mutation was found in exons $1-5$. In exon 6 , we identified a previously described polymorphism ( $r s 3856806)$ in 14 samples (22.2\%). One was homozygous $(1.6 \%)$ and 13 were heterozygous $(20.6 \%)$. This polymorphism does not affect the amino acid sequence of the PPAR $\gamma$ protein.

Qualitative RT-PCR. The human PPAR $\gamma$ gene has nine exons and alternate splicing generates 2 main transcripts, the PPAR $\gamma 1$ and PPAR $\gamma 2$ mRNAs, which differ at their 5'-ends. The 5'untranslated sequence of PPAR $\gamma 1$ is comprised of exons A1 and A2, whereas that of PPAR $\gamma 2$ plus the additional PPAR $\gamma 2$ specific N-terminal amino acids are encoded by exon B (31). We designed specific primers to selectively amplify PPAR $\gamma 1$ or PPAR $\gamma 2$ (Fig. 2A). In normal human kidney, CCRCC tumors and cell lines, PPAR $\gamma 1$ was expressed (Fig. 2B). In contrast, PPAR $\gamma 2$ was only detected in adipose tissue, used as a positive control.

Quantitative RT-PCR. The PPAR $\gamma$ gene has previously been shown to be expressed in CCRCC $(36,37)$. In an initial experiment, we compared PPAR $\gamma$ expression in a series of 20 CCRCC for which RNA extracted from the normal corresponding kidney was of good quality. We did not find any significant difference in PPAR $\gamma$ expression between normal and tumor tissues (data not shown). Similarly, immunohistochemistry did not allow us to demonstrate significant difference between CCRCC and normal kidney (unpublished data). We then assessed PPAR $\gamma$ expression in our 63 tumor 

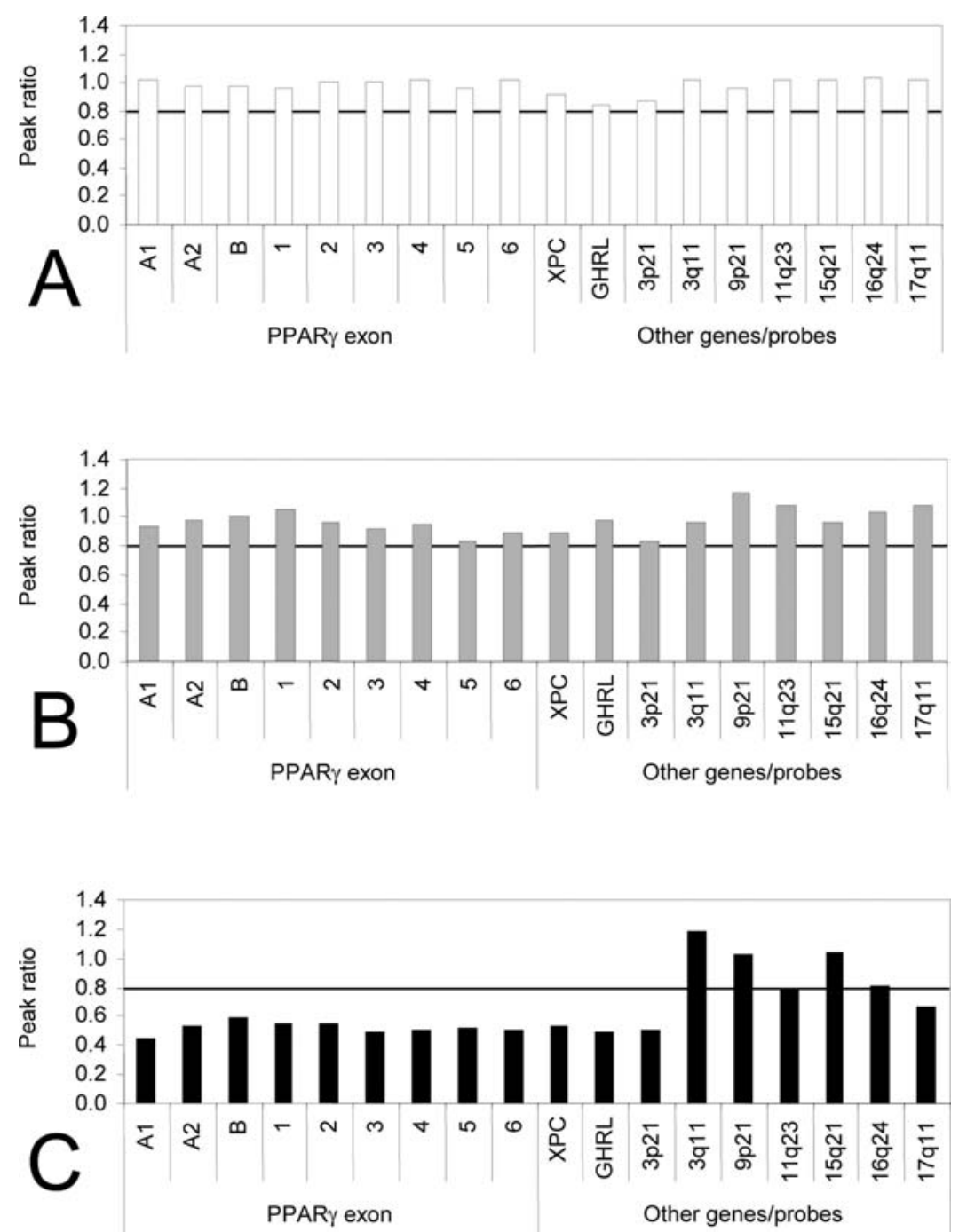

Figure 1. MLPA analysis of the PPAR gene in CCRCC. The $9 P P A R \gamma$ exons are represented on the left (A1-6) and the control probes on the right of the graph. Representative results from 3 types of samples are presented: a normal kidney (A), a tumor with no PPAR $\gamma$ deletion (B), and a sample presenting a large deletion in chromosome $3 p(C)$. For each sample and probe is presented the ratio of the results obtained with tumor DNA and a control DNA. The cut-off threshold (ratio $r=0.8$ ) is indicated by an horizontal lane on each graph.

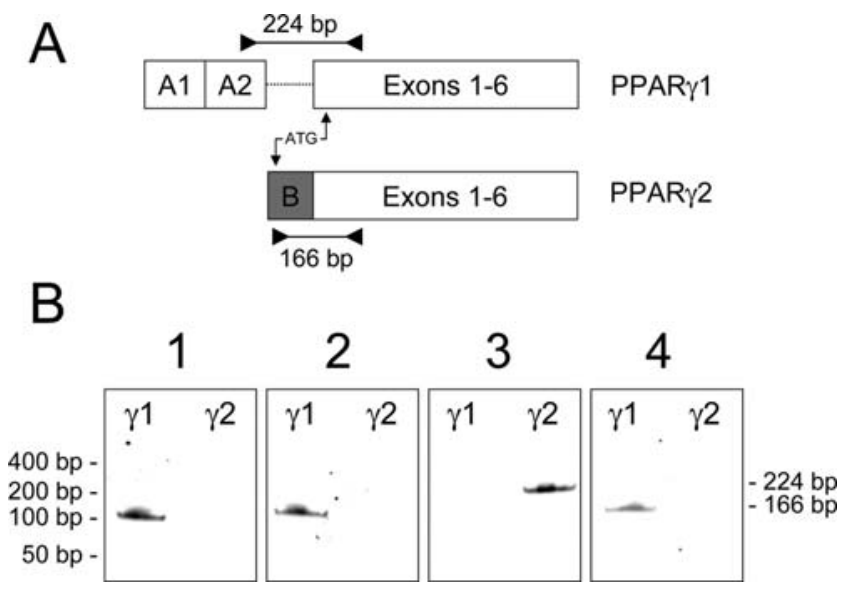

Figure 2. Qualitative RT-PCR analysis of PPAR $\gamma$ in CCRCC. (A) Schematic representation of the PPAR $\gamma 1$ and $\gamma 2$ transcripts. The specific primers are located on exons A2 and B, respectively. PCR were performed with a common anti-sense primer (exon 1). (B) Representative polyacrylamide gel electrophoresis showing expression of the different PPAR $\gamma$ transcripts in a CCRCC (1), normal kidney (2), adipose tissue (3), and the CCRCC 786-O cell-line (4). The size of both transcripts are presented on the right (PPAR $\gamma 1$, $166 \mathrm{bp}$; PPAR $\gamma 2,224$ bp). samples. All the tumors tested expressed PPAR $\gamma$ at the transcriptional level. Nevertheless, some differences appeared between tumors with different Fuhrman grades. Grade 4 tumors expressed significantly less PPAR $\gamma$ than the other grades $(\mathrm{p}<0.05)$. We also observed differences when comparing T3-T4 tumors and T1-T2 tumors, but the statistical analysis revealed that PPAR $\gamma$ expression did not correlate with the metastasis status (Fig. 3). Tumors presenting an allelic loss did not show a decreased PPAR $\gamma$ expression (not shown).

Western blot analysis. We analyzed PPAR $\gamma$ expression at the protein level in 23 tumor samples. All the samples tested showed a specific expression of PPAR $\gamma$. We then compared the normalized intensity between two groups of tumors: 8 high grade (Fuhrman 4) and 15 lower grade (Fuhrman grades 1,2 or 3). Intensity in the F4 group was not statistically different from the $\mathrm{F}(1+2+3)$ group of tumors (Fig. 4).

Cell line induction. Three CCRCC cell lines were treated with $10 \mu \mathrm{M}$ rosiglitazone for $24 \mathrm{~h}$. Expression of ANGPTL4, a known PPAR $\gamma$ target, was measured by real-time quantitative 

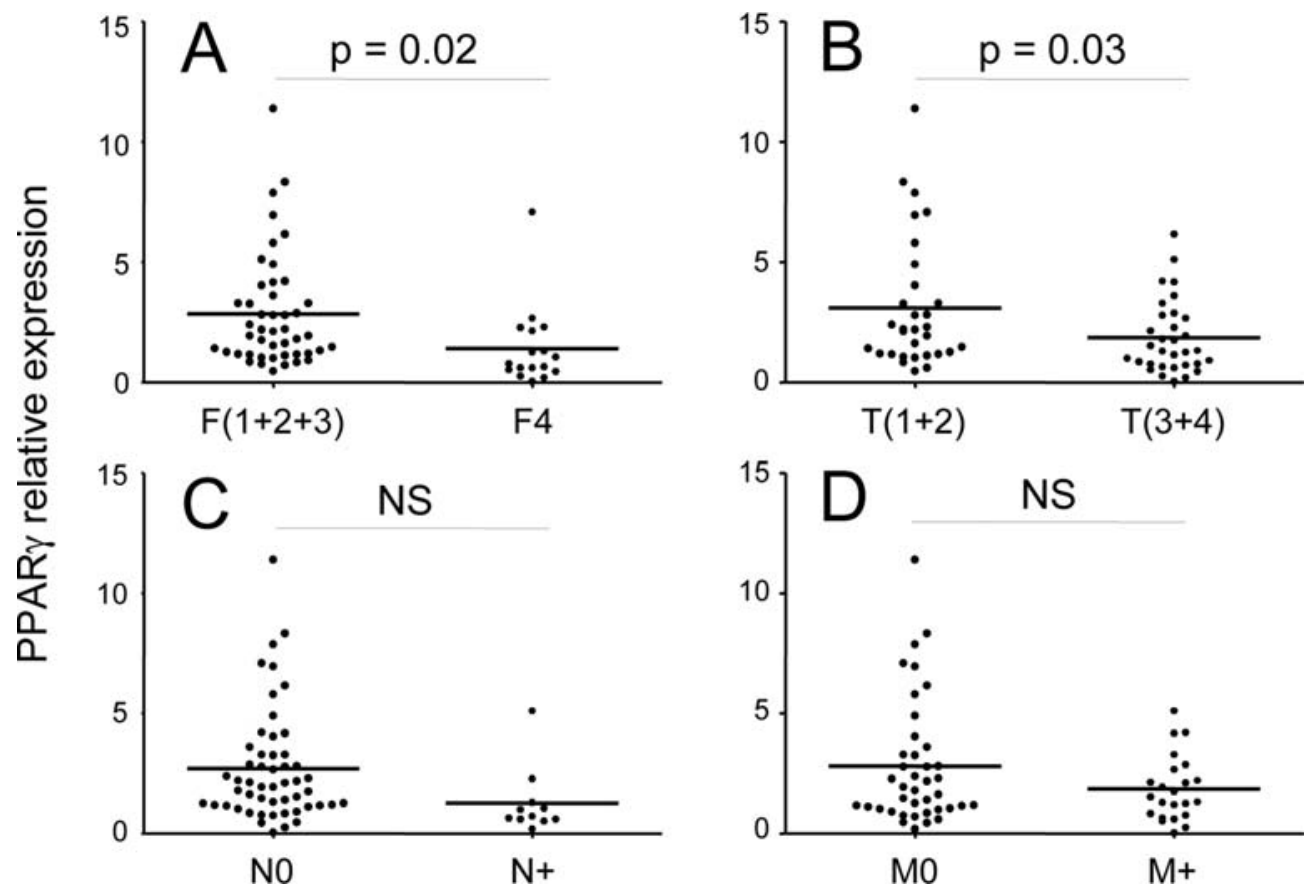

Figure 3. Quantitative real-time RT-PCR analysis of PPAR $\gamma$ in CCRCC tumors. The expression is significatively lower in patients with a high Fuhrman grade (A) or a higher T stage (B), but there is no difference according to lymph node involvement (C) and the presence of metastases (D). Horizontal lines represent mean values.

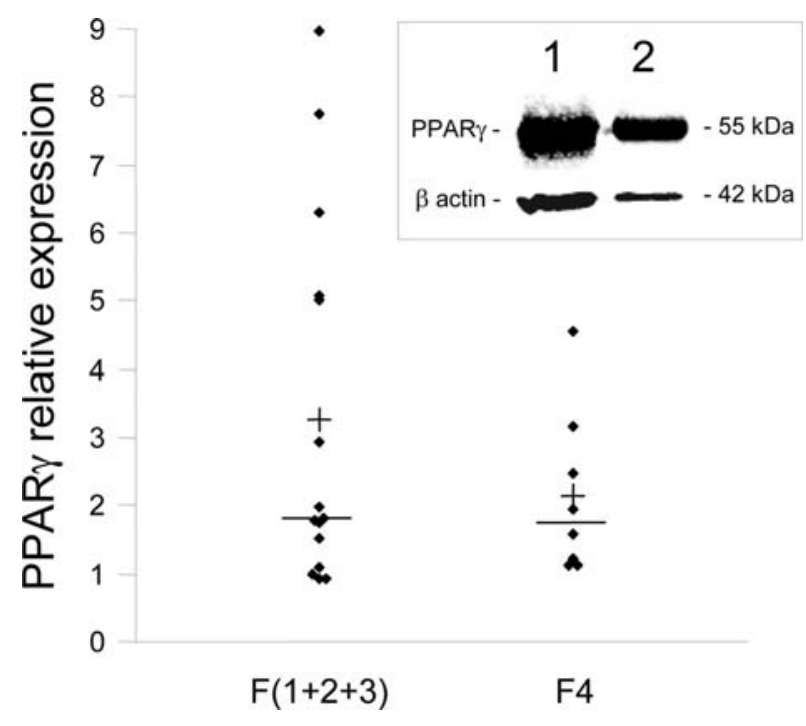

Figure 4. PPAR $\gamma$ expression by Western blot analysis according to Fuhrman grade. Proteins extracted from CCRCC were analyzed using a specific antiPPAR $\gamma$ antibody, and membranes were re-probed with an anti-actin antibody as normalization control. Representative results (1, 786-O cell line; 2, CCRCC) are presented in the insert. The quantification (ratio PPAR $\gamma / \beta$-actin) was performed after image analysis. Horizontal lines represent median values, (+) represent mean values. There was no difference between Fuhrman grade 4 and the other tumors (Fuhrman grades 1,2 or 3 ).

RT-PCR. PPAR $\gamma$ activation was found to induce ANGPTL4 expression in all cell lines, which induction ratios ranging from 3- (RCC4 cells) to 14-fold for the 786-O cells (Fig. 5). Significant effects were also noted when cells were treated with the natural PPAR $\gamma$ ligand, 15-deoxy- $\Delta^{12,14}$-prostaglandin

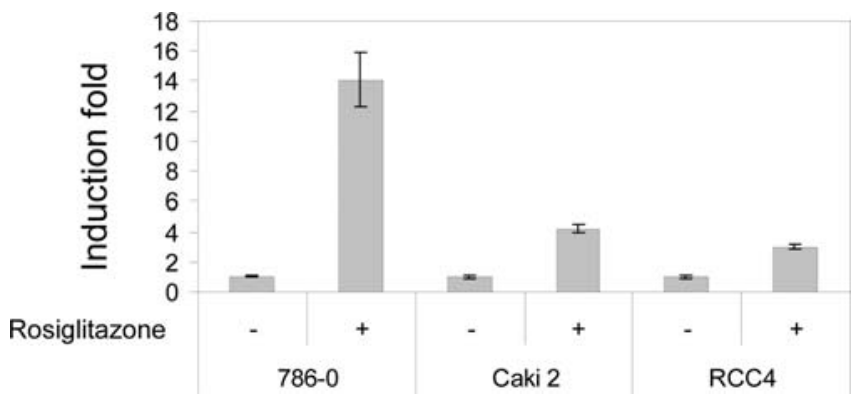

Figure 5. Expression of ANGPTL4, a PPAR $\gamma$ target gene, in CCRCC celllines in the absence (-) or in the presence $(+)$ of rosiglitazone. Induction rates were 14,4 and 3 , respectively.

$\mathrm{J}_{2}$ (not shown). Finally, SNAT4, a transporter of neutral amino acid of the solute carrier family (SLC38A4), which is also a PPAR $\gamma$ target (unpublished data), was also induced in these experiments (data not shown).

\section{Discussion}

Following binding of a natural agonist (e.g., 15-deoxy- $\Delta^{12,14}$ prostaglandin $\mathrm{J}_{2}$ ) or of a synthetic ligand (e.g., glitazones), PPAR $\gamma$ binds to the promoter region of target genes, and modulate their expression. Some of these ligands (rosiglitazone and pioglitazone) have been shown to enhance insulin sensitivity and to stimulate adipogenesis, and are therefore being used for the treatment of type II diabetes (38). Numerous reports have also highlighted the implication of PPAR $\gamma$ in cancer. In particular, effects of PPAR $\gamma$ agonists on tumor cell proliferation and on angiogenesis have been 
reported $(15,39,40)$. However, very few studies have been carried out on CCRCC, the major form of kidney cancer. In these in vitro studies, PPAR $\gamma$ agonists have also been shown to inhibit cell growth, to induce apoptosis of cancer cells, and finally to reduce the production of potent angiogenic factors such as VEGF and FGF (18-20). These results suggest that PPAR $\gamma$ agonists are potent inhibitors of angiogenesis and that PPAR $\gamma$ may be an interesting target for the treatment of advanced CCRCC.

An important prerequisite for PPAR $\gamma$ agonists to be used as anti-cancer agents is that PPAR $\gamma$ must be expressed and functional in cancer cells. Several reports have described the analysis of the PPAR gene in tumors. Such alterations turned out to be very rare events $(34,35,41,42)$. In our series of CCRCC, we only found a known polymorphism in $22.2 \%$ of the tumors. Interestingly, this polymorphism ( $r 3856806$ ) does not modify the protein sequence. Beside this polymorphism, we did not find any mutation in our series of CCRCC, which is in agreement with published data obtained with other tumor types.

In contrast, MLPA analysis allowed us to detect tumors presenting large heterozygous deletions on chromosome $3 \mathrm{p}$. This region harbors several tumor suppressor genes such as VHL, FHIT, RASSF-1 or genes involved in DNA repair such as MLH-1 $(43,44)$. Most of the CCRCC tumors of our collection $(70 \%)$ were deleted for $V H L$ and $57 \%$ showed large deletions on chromosome $3 \mathrm{p}$ (data not shown). All the tumors deleted for PPAR (14.3\% of our collection) were also deleted for $V H L$. But these tumors did not present a lower PPAR $\gamma$ expression level as determined by RT-PCR.

All the CCRCC tumors tested were found to express PPAR $\gamma$ as determined by RT-PCR and immunoblotting. Our results are in accordance with the report of Yang et al who presented a PPAR $\gamma$ expression at both mRNA and protein level in CCRCC tissues (19). We show here for the first time that the PPAR $\gamma 1$ isoform is expressed in these tissues. High grade tumors were found to present lower transcript levels, but immunoblotting experiments did not confirm this difference. Therefore, on this basis, it is tempting to speculate that PPAR $\gamma$ ligand might be effective in the treatment of CCRCC, independently of the Fuhrman grade of the tumor.

Finally, we show that in CCRCC cell lines, PPAR $\gamma$ activation by a synthetic ligand regulates target genes. One of them is ANGPTL4, a protein involved in angiogenesis pathway (45). We also found that SNAT4, a PPAR $\gamma$ target gene identified in colon cancer (unpublished data) was found to be regulated in all 3 CCRCC cell lines tested. Finally, in an effort to identify other PPAR $\gamma$ gene targets in CCRCC, we utilized DNA-microarray technology. The 786-O cell line was cultured for $24 \mathrm{~h}$ in the presence or in the absence or a PPAR $\gamma$ agonist (15-deoxy $\Delta^{12-14}$ prostaglandin $\mathrm{J}_{2}$ or rosiglitazone). RNA was then extracted, amplified and hybridized to pangenomic DNA microarrays. This allowed us to demonstrate significant changes in transcript levels following treatment (unpublished data). Altogether, these results demonstrate that PPAR $\gamma$ is functional in CCRCC cell lines.

The antiproliferative activity of PPAR $\gamma$ ligands observed in many human cancer cell lines suggests that these molecules may have promise as anticancer drugs. Unfortunately, no significant effect could be observed when troglitazone alone was administered in patients with metastatic colorectal cancer included in a phase II clinical trial (46). Recent reports demonstrated a synergy between PPAR $\gamma$ ligands and current anticancer therapies such as fluorouracil (47), carboplatin $(48,49)$ or tamoxifen $(50)$. Thus, it would be interesting to evaluate the effect of PPAR $\gamma$ ligand in clinical trials, alone or in combination with other molecules.

\section{Acknowledgments}

This work was supported by grants from the Ligue Départementale contre le Cancer (35, 44 and 56), the Association pour la Recherche contre le Cancer (ARC-3732) and from Région Bretagne (ACOMB 2627). We thank Stéphane Dréano (CNRS UMR 6061, Institut de Génétique et Développement) for technical support with the MLPA experiments, and the 'Centre de Ressources Biologiques du CHU de Rennes'.

\section{References}

1. Jemal A, Siegel R, Ward E, et al: Cancer Statistics, 2008. CA Cancer J Clin 58: 71-96, 2008.

2. Patard J-J, Pouessel D, Bensalah K and Culine S: Targeted therapy in renal cell carcinoma. World J Urol 26: 135-140, 2008.

3. Motzer RJ and Bukowski RM: Targeted therapy for metastatic renal cell carcinoma. J Clin Oncol 24: 5601-5608, 2006.

4. Motzer RJ, Hutson TE, Tomczak P, et al: Sunitinib versus interferon alfa in metastatic renal cell carcinoma. N Engl J Med 356: 115-124, 2007.

5. Berger J and Moller DE: The mechanism of action of PPARs. Annu Rev Med 53: 409-435, 2002.

6. Desvergne B and Wahli W: Peroxisome proliferator-activated receptors: nuclear control of metabolism. Endocr Rev 20: 649-688, 1999.

7. Rosen ED and Spiegelman BM: PPARgamma: a nuclear regulator of metabolism, differentiation, and cell growth. J Biol Chem 276: 37731-37734, 2001.

8. Fajas L, Debril MB and Auwerx J: Peroxisome proliferatoractivated receptor-gamma: from adipogenesis to carcinogenesis. J Mol Endocrinol 27: 1-9, 2001.

9. Sarraf P, Mueller E, Jones D, et al: Differentiation and reversal of malignant changes in colon cancer through PPARgamma. Nat Med 4: 1046-1052, 1998.

10. Wang X, Southard RC and Kilgore MW: The increased expression of peroxisome proliferator-activated receptor-gammal in human breast cancer is mediated by selective promoter usage. Cancer Res 64: 5592-5596, 2004.

11. Han S, Zheng Y and Roman J: Rosiglitazone, an agonist of PPARgamma, inhibits non-small cell carcinoma cell proliferation in part through activation of tumor sclerosis complex-2. PPAR Res 2007: 29632, 2007.

12. Martelli ML, Iuliano R, Le Pera I, et al: Inhibitory effects of peroxisome poliferator-activated receptor gamma on thyroid carcinoma cell growth. J Clin Endocrinol Metab 87: 4728-4735, 2002.

13. Fu YG, Sung JJ, Wu KC, et al: Inhibition of gastric cancer cells associated angiogenesis by $15 \mathrm{~d}$-prostaglandin $\mathrm{J} 2$ through the downregulation of angiopoietin-1. Cancer Lett 243: 246-254, 2006.

14. Koeffler HP: Peroxisome proliferator-activated receptor gamma and cancers. Clin Cancer Res 9: 1-9, 2003.

15. Wang T, Xu J, Yu X, Yang R and Han ZC: Peroxisome proliferator-activated receptor gamma in malignant diseases. Crit Rev Oncol Hematol 58: 1-14, 2006.

16. Yoshizumi T, Ohta T, Ninomiya I, et al: Thiazolidinedione, a peroxisome proliferator-activated receptor-gamma ligand, inhibits growth and metastasis of HT-29 human colon cancer cells through differentiation-promoting effects. Int J Oncol 25: 631-639, 2004.

17. Gupta RA, Brockman JA, Sarraf P, Willson TM and DuBois RN: Target genes of peroxisome proliferator-activated receptor gamma in colorectal cancer cells. J Biol Chem 276: 29681-29687, 2001. 
18. Yuan J, Takahashi A, Masumori N, et al: Ligands for peroxisome proliferator-activated receptor gamma have potent antitumor effect against human renal cell carcinoma. Urology 65: 594-599, 2005.

19. Yang FG, Zhang ZW, Xin DQ, et al: Peroxisome proliferatoractivated receptor gamma ligands induce cell cycle arrest and apoptosis in human renal carcinoma cell lines. Acta Pharmacol Sin 26: 753-761, 2005.

20. York M, Abdelrahim M, Chintharlapalli S, Lucero SD and Safe S: 1,1-Bis(3'-Indolyl)-1-(p-Substitutedphenyl)methanes induce apoptosis and inhibit renal cell carcinoma growth. Clin Cancer Res 13: 6743-6752, 2007.

21. Greene ME, Blumberg B, McBride OW, et al: Isolation of the human peroxisome proliferator activated receptor gamma cDNA: expression in hematopoietic cells and chromosomal mapping. Gene Expr 4: 281-299, 1995.

22. Barry RE and Krek W: The von Hippel-Lindau tumor suppressor: a multi-faceted inhibitor of tumorigenesis. Trends Mol Med 10: 466-472, 2004.

23. Shuin T, Kondo K, Torigoe S, et al: Frequent somatic mutations and loss of heterozygosity of the von Hippel-Lindau tumor suppressor gene in primary human renal cell carcinomas. Cancer Res 54: 2852-2855, 1994.

24. Patard JJ, Rioux-Leclercq N, Masson D, et al: Absence of VHL gene alteration and high VEGF expression are associated with tumor aggressiveness and poor survival of renal-cell carcinoma. Br J Cancer 101: 1417-1424, 2009.

25. Banks RE, Tirukonda P, Taylor C, et al: Genetic and epigenetic analysis of von Hippel-Lindau (VHL) gene alterations and relationship with clinical variables in sporadic renal cancer. Cancer Res 66: 2000-2011, 2006.

26. Fuhrman SA, Lasky LC and Limas C: Prognostic significance of morphologic parameters in renal cell carcinoma. Am J Surg Pathol 6: 655-663, 1982.

27. Rioux-Leclercq N, Karakiewicz PI, Trinh QD, et al: Prognostic ability of simplified nuclear grading of renal cell carcinoma. Cancer 109: 868-874, 2007.

28. Guinan P, Sobin LH, Algaba F, et al: TNM staging of renal cell carcinoma: Workgroup No. 3. Union International Contre le Cancer (UICC) and the American Joint Committee on Cancer (AJCC). Cancer 80: 992-993, 1997.

29. Ficarra V, Guille F, Schips L, et al: Proposal for revision of the TNM classification system for renal cell carcinoma. Cancer 104: 2116-2123, 2005

30. Schouten JP, McElgunn CJ, Waaijer R, Zwijnenburg D, Diepvens F and Pals G: Relative quantification of 40 nucleic acid sequences by multiplex ligation-dependent probe amplification. Nucleic Acids Res 30: e57, 2002.

31. Fajas L, Auboeuf D, Raspe E, et al: The organization, promoter analysis, and expression of the human PPARgamma gene. J Biol Chem 272: 18779-18789, 1997.

32. Blanchot-jossic F, Jarry A, Masson D, et al: Up-regulated expression of ADAM17 in human colon carcinoma: co-expression with EGFR in neoplastic and endothelial cells. J Pathol 207: 156-163, 2005 .

33. Rageul J, Mottier S, Jarry A, et al: KLF4-dependent, PPARgamma-induced expression of GPA33 in colon cancer cell lines. Int J Cancer 125: 2802-2809, 2009.
34. Sarraf P, Mueller E, Smith WM, et al: Loss-of-function mutations in PPAR gamma associated with human colon cancer. Mol Cell 3: 799-804, 1999.

35. Ikezoe T, Miller CW, Kawano S, et al: Mutational analysis of the peroxisome proliferator-activated receptor gamma gene in human malignancies. Cancer Res 61: 5307-5310, 2001.

36. Matsuyama M and Yoshimura R: A novel approach to anticancer therapies: peroxisome proliferator activator-receptor-gamma as a new target therapy in the treatment of human urological cancer. Endocr Metab Immune Disord Drug Targets 9: 76-83, 2009.

37. Yuan J, Takahashi A, Masumori N, Itoh $\mathrm{N}$ and Tsukamoto T: Peroxisome proliferator-activated receptor gamma is frequently underexpressed in renal cell carcinoma. Int J Urol 13: 265-270, 2006.

38. Hauner H: The mode of action of thiazolidinediones. Diabetes Metab Res Rev 18 (Suppl. 2): S10-S15, 2002.

39. Margeli A, Kouraklis $\mathrm{G}$ and Theocharis S: Peroxisome proliferator activated receptor-gamma (PPAR-gamma) ligands and angiogenesis. Angiogenesis 6: 165-169, 2003.

40. Han S and Roman J: Peroxisome proliferator-activated receptor gamma: a novel target for cancer therapeutics? Anticancer Drugs 18: 237-244, 2007.

41. Bouancheau D, Buecher B, Jarry A, et al: The PPAR(gamma) K422Q mutation does not contribute to troglitazone inefficiency in colon cancer treatment. Cancer Lett 224: 111-116, 2005.

42. Posch MG, Zang C, Mueller W, Lass U, von Deimling A and Elstner E: Somatic mutations in peroxisome proliferator-activated receptor-gamma are rare events in human cancer cells. Med Sci Monit 10: BR250-254, 2004.

43. Thrash-Bingham CA, Salazar H, Freed JJ, Greenberg RE and Tartof KD: Genomic alterations and instabilities in renal cell carcinomas and their relationship to tumor pathology. Cancer Res 55: 6189-6195, 1995.

44. Sukosd F, Kuroda N, Beothe T, Kaur AP and Kovacs G: Deletion of chromosome 3p14.2-p25 involving the VHL and FHIT genes in conventional renal cell carcinoma. Cancer Res 63: 455-457, 2003.

45. Le Jan S, Amy C, Cazes A, et al: Angiopoietin-like 4 is a proangiogenic factor produced during ischemia and in conventional renal cell carcinoma. Am J Pathol 162: 1521-1528, 2003.

46. Kulke MH, Demetri GD, Sharpless NE, et al: A phase II study of troglitazone, an activator of the PPARgamma receptor, in patients with chemotherapy-resistant metastatic colorectal cancer. Cancer J 8: 395-399, 2002.

47. Zhang YQ, Tang XQ, Sun L, et al: Rosiglitazone enhances fluorouracil-induced apoptosis of HT-29 cells by activating peroxisome proliferator-activated receptor gamma. World J Gastroenterol 13: 1534-1540, 2007.

48. Girnun GD, Chen L, Silvaggi J, et al: Regression of drugresistant lung cancer by the combination of rosiglitazone and carboplatin. Clin Cancer Res 14: 6478-6486, 2008.

49. Girnun GD, Naseri E, Vafai SB, et al: Synergy between PPARgamma ligands and platinum-based drugs in cancer. Cancer Cell 11: 395-406, 2007.

50. Yu HN, Noh EM, Lee YR, et al: Troglitazone enhances tamoxifen-induced growth inhibitory activity of MCF-7 cells. Biochem Biophys Res Commun 377: 242-247, 2008. 